\title{
Enhanced synaptic activity and epileptiform events in the embryonic KCC2 deficient hippocampus
}

\author{
Ilgam Khalilov ${ }^{1,2,3 \neq}$, Geneviève Chazal ${ }^{1,2,3 \neq}$, Ilona Chudotvorova ${ }^{1,2,3}{ }^{\dagger}$, Christophe Pellegrino ${ }^{1,2,3}$, Séverine \\ Corby ${ }^{1,2,3}$, Nadine Ferrand ${ }^{1,2,3}$, Olena Gubkina ${ }^{1,2,3}$, Romain Nardou ${ }^{1,2,3}$, Roman Tyzio 1,2,3, Sumii Yamamoto ${ }^{1,2,3}$, \\ Thomas J. Jentsch ${ }^{4}$, Christian A. Hübner ${ }^{5}$, Jean-Luc Gaiarsa ${ }^{1,2,3}$, Yehezkel Ben-Ari ${ }^{1,2,3}$ and Igor Medina ${ }^{1,2,3 *}$ \\ 1 INSERM Unité 901, Marseille, France \\ 2 Université de la Méditerranée, UMR S901 Aix-Marseille 2, Marseille, France \\ ${ }^{3}$ Institut de Neurobiologie de la Méditerranée, Marseille, France \\ ${ }^{4}$ Leibniz-Institut für Molekulare Pharmakologie (FMP) and Max-Delbrück-Centrum für Molekulare Medizin (MDC), Berlin, Germany \\ ${ }^{5}$ Institut für Humangenetik, University Hospital Jena, Friedrich Schiller University Jena, Jena, Germany
}

\section{Edited by:}

Enrico Cherubini, International School for Advanced Studies, Italy

\section{Reviewed by:}

Kai Kaila, University of Helsinki,

Finland

Raúl Eduardo Russo, Instituto de Investigaciones Biológicas Clemente Estable, Uruguay

\section{*Correspondence:}

Igor Medina, Institut de Neurobiologie de la Méditerranée/INSERM Unité 901, 163 Route de Luminy, 13273

Marseille, France.

e-mail: medina@inmed.univ-mrs.fr

\section{${ }^{\dagger}$ Present address:}

Ilona Chudotvorova, Brandeis

University, 415 South Street,

Waltham, MA 02453, USA.

‡llgam Khalilov and Geneviève Chazal have contributed equally to this work.
The neuronal potassium-chloride co-transporter 2 [indicated thereafter as KCC2 (for protein) and $K c c 2$ (for gene)] is thought to play an important role in the post natal excitatory to inhibitory switch of GABA actions in the rodent hippocampus. Here, by studying hippocampi of wild-type $\left(\mathrm{KcC2}^{+/+}\right)$and $\mathrm{Kcc} 2$ deficient $\left(\mathrm{KcC2}^{-/-}\right)$mouse embryos, we unexpectedly found increased spontaneous neuronal network activity at E18.5, a developmental stage when KCC2 is thought not to be functional in the hippocampus. Embryonic $\mathrm{Kcc}^{-1-}$ hippocampi have also an augmented synapse density and a higher frequency of spontaneous glutamatergic and GABA-ergic postsynaptic currents than naïve age matched neurons. However, intracellular chloride concentration $\left(\left[\mathrm{Cl}^{-}\right]_{i}\right)$ and the reversal potential of GABAmediated currents $\left(\mathrm{E}_{\mathrm{GABA}}\right)$ were similar in embryonic $\mathrm{KCC2}^{+/+}$and $\mathrm{KCC2}^{-/-} \mathrm{CA} 3$ neurons. In addition, KCC2 immunolabeling was cytoplasmic in the majority of neurons suggesting that the molecule is not functional as a plasma membrane chloride co-transporter. Collectively, our results show that already at an embryonic stage, KCC2 controls the formation of synapses and, when deleted, the hippocampus has a higher density of GABA-ergic and glutamatergic synapses and generates spontaneous and evoked epileptiform activities. These results may be explained either by a small population of orchestrating neurons in which KCC2 operates early as a chloride exporter or by transporter independent actions of KCC2 that are instrumental in synapse formation and networks construction.

Keywords: GABA, KCC2, neuron, development, synapse, network

\section{INTRODUCTION}

$K c c 2$ is a potassium-chloride co-transporter that is exclusively expressed in neurons of central nervous system (CNS; Payne et al., 1996; Williams et al., 1999). It plays an important role in regulating intracellular chloride concentrations $\left(\left[\mathrm{Cl}^{-}\right]_{\mathrm{i}}\right)$, thereby heavily impacting the magnitude of the inhibitory action of GABA in physiological processes (Rivera et al., 1999). In a wide range of animal species and brain structures, $\left[\mathrm{Cl}^{-}\right]_{\mathrm{i}}$ is elevated in immature neurons leading to depolarizing and often excitatory actions of GABA (Ben-Ari et al., 1989, 2007; Leinekugel et al., 1997, 1999; Owens and Kriegstein, 2002; Caiati et al., 2010). GABA acquires progressively its hyperpolarizing actions in a time and brain structure dependent manner. In hippocampus of rat and mice, it is roughly completed by the second postnatal week. Extensive investigations suggest that this developmental sequence is determined by a progressive reduction of the NKCC1 chloride importer and a parallel progressive enhanced operation of the KCC2 chloride exporter (Rivera et al., 1999; Gulyas et al., 2001; Stein et al., 2004). The expression of KCC2 is thought to lead to a reduction of $\left[\mathrm{Cl}^{-}\right]_{\mathrm{i}}$ and a shift of the actions of GABA from excitation to inhibition, although other chloride regulators - channels and transporters - take part in this sequence (Medina and Chudotvorova, 2006; Blaesse et al., 2009).

Several observations suggest that KCC2 is less operational in immature than adult neurons. Thus, in the hippocampus of mice and rats KCC2 labeling is first detected at the end of embryonic development, peaking during the second postnatal week (Stein et al., 2004; Blaesse et al., 2006). KCC2 starts reducing $\left[\mathrm{Cl}^{-}\right]_{\mathrm{i}}$ in hippocampal pyramidal neurons 5 days after birth in rats (Khirug et al., 2005; Nardou et al., 2011). In addition, at P0-P1, KCC2 is in an inactive phosphorylated form (Rinehart et al., 2009) and forms monomers (Blaesse et al., 2006), whereas in mature structures (>P20), KCC2 is dephosphorylated (Rinehart et al., 2009) and is expressed as multimers (Blaesse et al., 2006). Collectively these studies suggest that in cortical structures of mice and rats the KCC2 is not functional as a transporter during embryonic development, starting to contribute to the neuronal ion homeostasis during the first postnatal week and becoming fully operational at P10-P15. 
If KCC2 is not operative in embryos, its inactivation is expected to bear little effects on the embryonic maturation of brain networks. We now report that already at E18.5, $\mathrm{Kcc}^{-1-}$ mice hippocampal networks generate spontaneous epileptiform events and neurons have more GABA-ergic and glutamatergic synapses and currents than wild-type embryos $\left(K c c 2^{+/+}\right)$suggesting a requirement for the co-transporter in embryos. Yet, perforated patch-clamp recordings revealed no significant difference of $\left[\mathrm{Cl}^{-}\right]_{\mathrm{i}}$ between embryonic $\mathrm{Kcc} 2^{-/-}$and $\mathrm{Kcc} 2^{+/+}$hippocampal neurons and KCC2 was primarily cytoplasmic in $\mathrm{Kcc} 2^{+/+}$suggesting that the co-transporter does not control $\left[\mathrm{Cl}^{-}\right]_{\mathrm{i}}$ in most embryonic pyramidal neurons of the hippocampus. These results are compatible with either a transport-unrelated function of embryonic KCC2 acting to control synapse formation and the emergence of networks and/or a cell autonomous action of KCC2 regulating $\left[\mathrm{Cl}^{-}\right]_{\mathrm{i}}$ in a small population of instructive neurons that play major roles in neuronal growth, synapse formation and network activity.

\section{MATERIALS AND METHODS ANIMALS AND GENOTYPING}

The study was performed on E18.5 embryos of $\mathrm{Kcc} 2^{+/+}$and $K c c 2^{-1-}$ mice as characterized previously (Hubner et al., 2001). The animal care and handling was performed in accordance with the guidelines of the European Union Council and the INSERM regulations on the use of laboratory animals.

\section{HIPPOCAMPAL PREPARATION}

Intact hippocampi were prepared as described previously (Khalilov et al., 1997). After cervical dislocation, the brain was removed quickly and submerged in ice-cold oxygenated (95\% $\mathrm{O}_{2} / 5 \% \mathrm{CO}_{2}$ ), choline-containing artificial CSF (ACSF) cutting solution, (in $\mathrm{mM}$ ): 110 choline chloride, $2.5 \mathrm{KCl}, 1.25 \mathrm{NaH}_{2} \mathrm{PO}_{4}$, $0.5 \mathrm{CaCl}_{2}, 7 \mathrm{MgCl}_{2}, 25 \mathrm{NaHCO}_{3}, 7 \mathrm{D}$-glucose, $\mathrm{pH}$ 7.4. The hemispheres were separated, and after removing the cerebellum, the frontal part of the neocortex, and surrounding structures, intact hippocampi were dissected from the septohippocampal complex and transferred into a beaker containing oxygenated ACSF containing (in mM):126 NaCl, 3.5 KCl, $2.0 \mathrm{CaCl}_{2}, 1.3$ $\mathrm{MgCl}_{2}, 25 \mathrm{NaHCO}_{3}, 1.2 \mathrm{NaH}_{2} \mathrm{PO}_{4}$, and 11 D-glucose (pH 7.4) and incubated at least $1 \mathrm{~h}$ before use. The intact hippocampi were placed into the conventional fully submerged chamber and superfused with oxygenated ACSF $\left(30-32^{\circ} \mathrm{C}, 5-6 \mathrm{ml} / \mathrm{min}\right)$. The hippocampi were fixed by entomological needles to the sylgard-covered bottom.

Extracellular field potentials and multi unit activities (MUA) were recorded in the intact in vitro hippocampal preparations using tungsten wire electrodes (diameter: $50 \mu \mathrm{m}$, California Fine Wire, Grover Beach, CA, USA) and a low-noise multichannel DAM-8A amplifiers (WPI, GB; low filter: $0.1 \mathrm{~Hz}$; high filter: $3 \mathrm{kHz}$; $\times 1000)$. Electrical stimulations were performed with a bipolar electrode (10-20 V, $40 \mu \mathrm{s})$. The signals were digitized using an analog-to-digital converter (Digidata 1440A, Axon Instruments, USA). pCLAMP 10.0.1.10 and Clampfit 10.1 (Axon Instruments, USA), MiniAnalysis 6.03 (Synaptosoft, Decatur, CA, USA) and Origin 7.5 (Microcal Software, USA) programs were used for the acquisition and analysis of Extracellular field potentials and MUA.

\section{ACUTE HIPPOCAMPAL SLICES}

Hippocampal transverse slices $(300 \mu \mathrm{m})$ from the middle portion of each hippocampus were cut with a vibrating microtome (Leica VT 1000S, Germany) in ice-cold oxygenated $\left(95 \% \mathrm{O}_{2} / 5 \% \mathrm{CO}_{2}\right)$, choline-replaced ACSF and were incubated at room temperature in ACSF. Slices were allowed to recover for at least $90 \mathrm{~min}$ before recording.

Whole-cell recordings were performed from CA3 area in voltage clamp mode at different holding potential using Axopatch 200B (Axon Instruments, USA). The whole-cell patch pipettes had a resistance of 6-8 M $\Omega$ when filled with solution containing (in $\mathrm{mM}$ ): 110 cesium methanesulfonate, $20 \mathrm{CsCl}, 10$ HEPES, $2 \mathrm{MgCl}_{2}$, 1 EGTA, 10 Na-phosphocreatine, 4 ATP-Mg, and 0.4 GTP-Na. The $\mathrm{pH}$ of the intracellular solutions was adjusted to 7.2 and the osmolarity to $280-290 \mathrm{mOsmoll}^{-1}$. The access resistance (15-30 M $\Omega$ ) and input resistance (1-2 G $\Omega$ ) were continuously monitored throughout the experiment. Occasional recordings with higher access resistance, lower input resistance, or those that displayed more than $20 \%$ changes in access and input resistances were discarded from analysis. External stimuli were applied using bipolar electrodes placed in the stratum radiatum (CA3 region). Stimulation intensity was adjusted during the first min of whole-cell recording to evoke $10-20 \mathrm{pA}$ responses.

Gramicidin-perforated patch-clamp recordings were performed as described previously (Tyzio et al., 2003).

Drugs used were purchased from Sigma, (4-aminopyridine, 4-AP) or Tocris (bicuculline, CNQX, D-APV).

\section{IMMUNOHISTOCHEMISTRY}

The expression of KCC2 was studied by immunohistochemistry. Brains from E18.5 mice were fixed in paraformaldehyde $4 \%$ for $24 \mathrm{~h}$, then embedded in optical cutting temperature (OCT) compound (Tissue-Tek, Sakura Finetek Inc., NL, USA) before serially cut, in $15 \mu \mathrm{m}$ sections, with a cryostat. Selected sections were processed for immunocytochemistry. They were first incubated for $2 \mathrm{~h}$, at room temperature, with a mixture of $5 \%$ normal goat serum (NGS) in PBS with $0.3 \%$ Triton X100. They were then, incubated overnight at $4{ }^{\circ} \mathrm{C}$ with the primary antibody diluted in PBS with $1 \%$ NGS and $0.1 \%$ Triton X100. After rinsing in PBS, sections were incubated with the fluorescent-labeled secondary antibody (1/1000, Chemicon, France) for $1 \mathrm{~h}$ at room temperature. The primary antibodies were an anti-KCC2 antibody (rabbit; dilution 1/1000; US Biological, Euromedex, France) or an anti-synaptophysin antibody (mouse, dilution 1/150, Chemicon, France).

Images were taken using a Zeiss confocal microscope (Wetzlar, Germany). The quantitative analysis of the fluorescence was performed in blind using Metamorphe software (Roper Scientific, USA). For analysis, on each image we manually drew regions comprising stained tissue and excluding nuclei and casual irregularities (empty spaces). The threshold of the detection of fluorescence clusters was set as Mean $+3 \mathrm{SD}$ of the fluorescence level in $\mathrm{Kcc}^{-1-}$ sections. The classification of the KCC2-positive neurons to groups "cytoplasm" or "membrane region" was done manually relying on the detectable fluorescence band on the periphery or center of the cell. All acquisitions and analysis were done blind. 


\section{RESULTS}

\section{EPILEPTIFORM EVENTS IN EMBRYONIC Kcc2 $^{-1-}$ HIPPOCAMPUS}

Field recordings of ongoing neuronal activity in intact hippocampi isolated from E18.5 Kcc2 $2^{+/+}$and $K c c 2^{-/-}$embryos revealed major differences between genotypes. In accordance with earlier studies, wild-type hippocampi generated the characteristic network recurrent population events that were reminiscent of giant depolarizing potentials (GDPs; Ben-Ari et al., 1989, 2007; Khalilov et al., 1999). In striking contrast, in $\mathrm{Kcc} 2^{-/-}$hippocampi, the spontaneous network events were significantly more frequent, longer-lasting, had higher amplitudes, and contained more spikes (Figures 1A,B). Another difference was that while in wild-type hippocampi 98.3\% of spontaneous events had characteristic bi-phasic form (examples in Figures 1A and 2A, six experiments, 10 analyzed events per experiment), in $K c c 2^{-l-}$ hippocampi the majority of spontaneous events $(72.7 \%, n=5,30$ events per experiment) had sharp tri-phasic form (see example in Figure 2B). These electrical activities were similar to epileptiform events observed in epileptic tissue (Cohen et al., 2002; Khalilov et al., 2003; Nardou et al., 2009, 2011; Wittner et al., 2009). Consistent with different spontaneous activities, evoked field potentials in $K c c 2^{-/-}$hippocampi differed clearly from those evoked in $\mathrm{Kcc}^{+/+}$structures (Figures 1A,B).

To characterize the contribution of GABA-ergic and glutamatergic neurotransmission into generation of the spontaneous network activities we first exposed acute hippocampi to a CNQX, a blocker of AMPA receptors, and found that it fully abolished spontaneous events in both $K c c 2^{+/+}$and $K c c 2^{-/-}$hippocampi (not shown, $n=5$ per condition). By contrast, the application of Bicuculline, a $\mathrm{GABA}_{\mathrm{A}}$ receptor antagonist, exerted different effects on $\mathrm{Kcc}^{+/+}$and $\mathrm{Kcc} 2^{-/-}$hippocampi. In wild-type structure it produced a transient $(4-5 \mathrm{~min})$ inhibition of the spontaneous GDPs (Figure 2A). During first $4 \mathrm{~min}$ of the exposure to bicuculline the frequency decreased more than fourfold from $(3.5 \pm 0.5) \times 10^{-3} \mathrm{~Hz}$ to $(0.6 \pm 0.1) \times 10^{-3} \mathrm{~Hz}, n=6$. This is in keeping with the important contribution of depolarizing GABA in their generation (see Ben-Ari et al., 1989; Khalilov et al., 1999; Ben-Ari et al., 2007; Cherubini et al., 2011). However, within longer time, the bicuculline led to the generation of interictallike events (IILE) $\left[(6.8 \pm 0.7) \times 10^{-3} \mathrm{~Hz}, n=6\right]$ reflecting the dual action of GABA, a depolarization, and a shunting action that, when blocked, enhances neuronal excitability (Khalilov et al., 1999). In contrast to naïve hippocampi, the ongoing spontaneous network activities recorded in $K c c 2^{-/-}$hippocampi were fully blocked by bicuculline even during long-lasting applications. As shown in Figure 2B, ongoing activity did not re-appear even after $>20$ min of application $(n=5)$. To unravel synchronized activities, we applied the $\mathrm{K}^{+}$channel blocker 4-aminopyridine (4-AP, $100 \mu \mathrm{M}, n=6)$ that triggered IILEs similar to those observed spontaneously prior to the application of bicuculline (Figure $2 \mathbf{B}$ ). Thus, embryonic $K c c 2^{-l-}$ hippocampi generate spontaneous events that require depolarizing/excitatory actions of GABA as they are fully blocked by GABA receptor antagonists. Yet, the properties of these events are reminiscent of events recorded in epileptic tissues (Cohen et al., 2002; Khalilov et al., 2003). Understanding of the cellular and molecular perturbations leading to

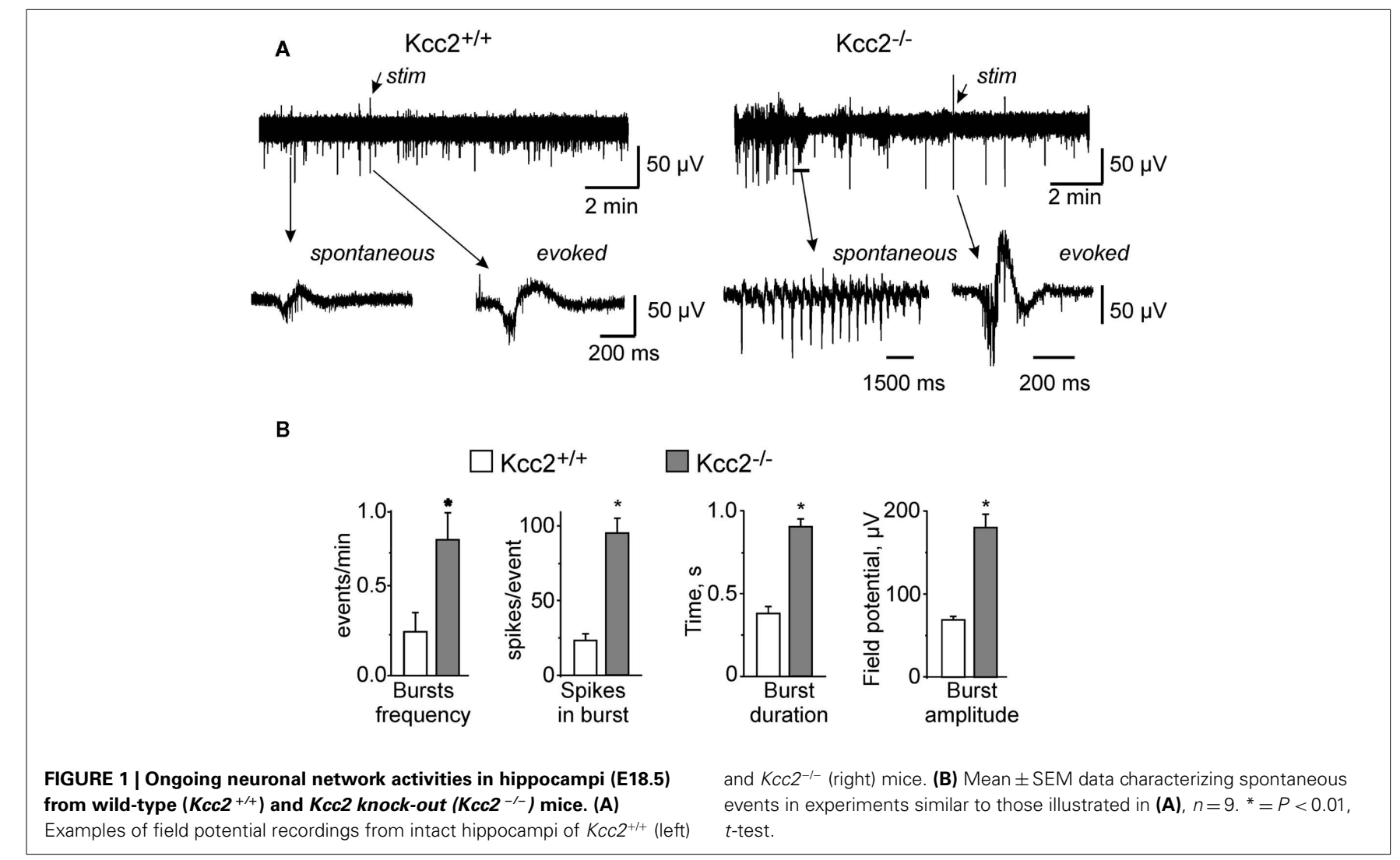




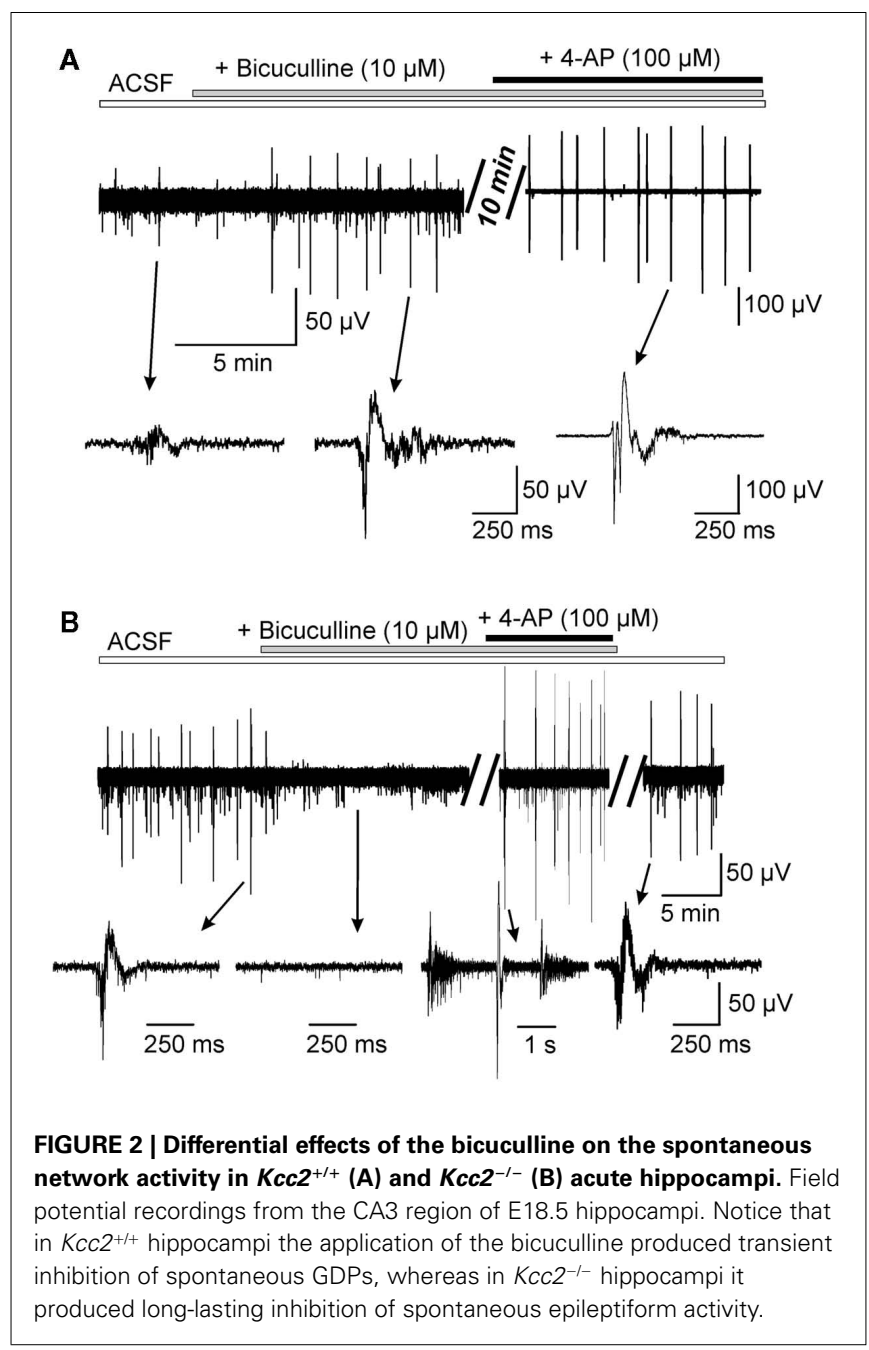

change of the network properties in embryonic $K c c 2^{-/-}$hippocampi and in epileptic tissue is an important subject for separate study.

\section{PREMATURE FUNCTIONAL EXPRESSION OF GLUTAMATERGIC PSCs IN KcC2 $^{-1-}$ NEURONS}

To determine the alterations of GABA and glutamatergic postsynaptic currents (PSCs) in $K c c 2^{-/-}$in comparison to naïve neurons, we used whole-cell recordings from CA3 pyramidal neurons. We showed previously that in immature rat hippocampus most of CA1 pyramidal neurons are silent (Tyzio et al., 1999). In agreement with this, 14 out of 19 neurons recorded in E18.5 Kcc2 ${ }^{+/+}$ mice hippocampi were fully silent, generating neither spontaneous nor evoked PSCs (Figure 3 $\mathbf{A}_{1}$ ), four neurons showed GABA PSCs (Figure $\mathbf{3 A}_{3,4}$ ), one neuron generated both GABA and glutamate PSCs but none had only glutamate PSCs as summarized in Figure 3D. In striking contrast, in $\mathrm{Kcc} 2^{-1-}$ slices most neurons were already active at the same age; only 5 out of 22 recorded neurons were silent, 17 neurons showed spontaneous GABA-ergic and/or glutamatergic PSCs (Figures 3B,D). Also, electrical stimuli generated long-lasting multisynaptic responses in $\mathrm{Kcc} 2^{-1-}$ slices that were never observed in $K c c 2^{+/+}$slices $(n=19$; Figure 3C).
A
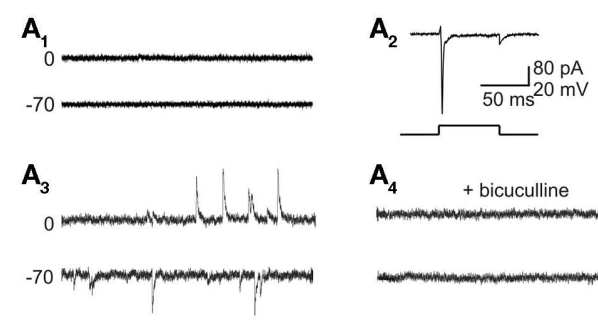

$\mathbf{A}_{4} \quad+$ bicuculline
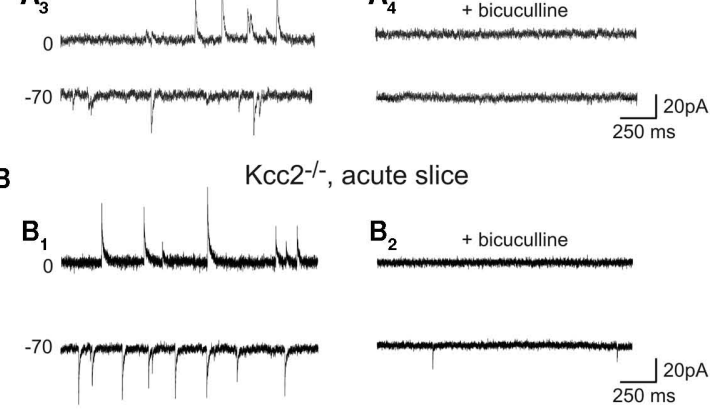

cc2-/-, acute slice

C

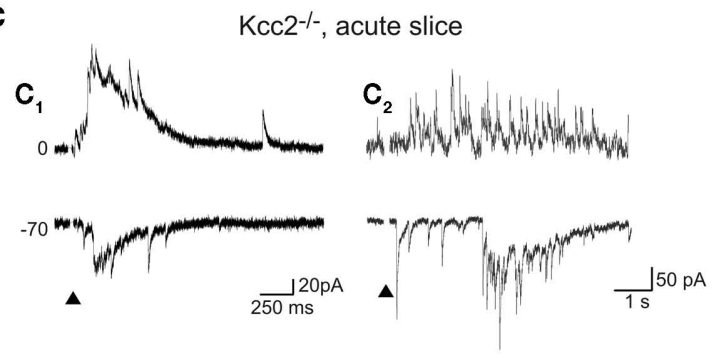

D $\square$ silent $\square$ IPSCs + EPSCs

$\square$ EPSCs only $\square$ IPSCs only

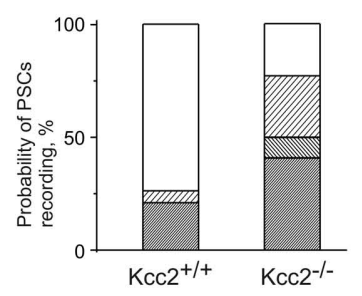

FIGURE 3 | Increased synaptic activity of CA3 pyramidal neurons in Kcc2 $\mathbf{2}^{-1}$ hippocampus. (A) Representative recordings of spontaneous synaptic activity in slices from $\mathrm{Kcc} 2^{+/+}$mouse hippocampus. Most neurons were synaptically silent $\left(\mathbf{A}_{1}\right)$ although spikes could be induced by the application of positive voltage step $\left(\mathbf{A}_{\mathbf{2}}\right)$. Only few neurons showed spontaneous synaptic activity $\left(\mathbf{A}_{3}\right)$. In the illustrated neuron all postsynaptic currents were GABA-mediated (GABA PSCs) as they had long-lasting kinetic, reversed at $-30 \mathrm{mV}$ and were inhibited by bicuculline $\left(\mathbf{A}_{4}\right)$. (B) Spontaneous postsynaptic currents in $K c \mathrm{c} 2^{--}$neurons $\left(\mathbf{B}_{1}\right)$. Application of bicuculline revealed the presence of spontaneous glutamatergic postsynaptic currents (glutamate PSCs) at $V_{\mathrm{h}}=-70 \mathrm{mV}\left(\mathbf{B}_{2}\right)$. The amplitude and kinetic of electrically isolated spontaneous GABA PSCs $\left(V_{h}=0 \mathrm{mV}\right)$ did not differ in $\mathrm{KcC2}^{+/+}$and $\mathrm{KcC2}^{-/-}$neurons (statistics not shown). (C) Evoked postsynaptic responses in $\mathrm{KCC}^{-1-}$ neurons lasting from hundreds of milliseconds $\left(\mathbf{C}_{1}\right)$ to few seconds $\left(\mathbf{C}_{2}\right)$. (D) Relative proportion of silent neurons and neurons generating spontaneous GABA PSCs and/or glutamate PSCs in CA3 region of $\mathrm{CCC}^{+/+}$(19 neurons, six experiments) and $\mathrm{KCC2}^{-1-}$ (22 neurons, six experiments) hippocampal slices.

Consistent with the electrophysiology data, immunolabeling with anti-synaptophysin antibody revealed significant differences between $\mathrm{Kcc}^{-/-}$and $\mathrm{Kcc} 2^{+/+}$hippocampal sections (Figure 4). 


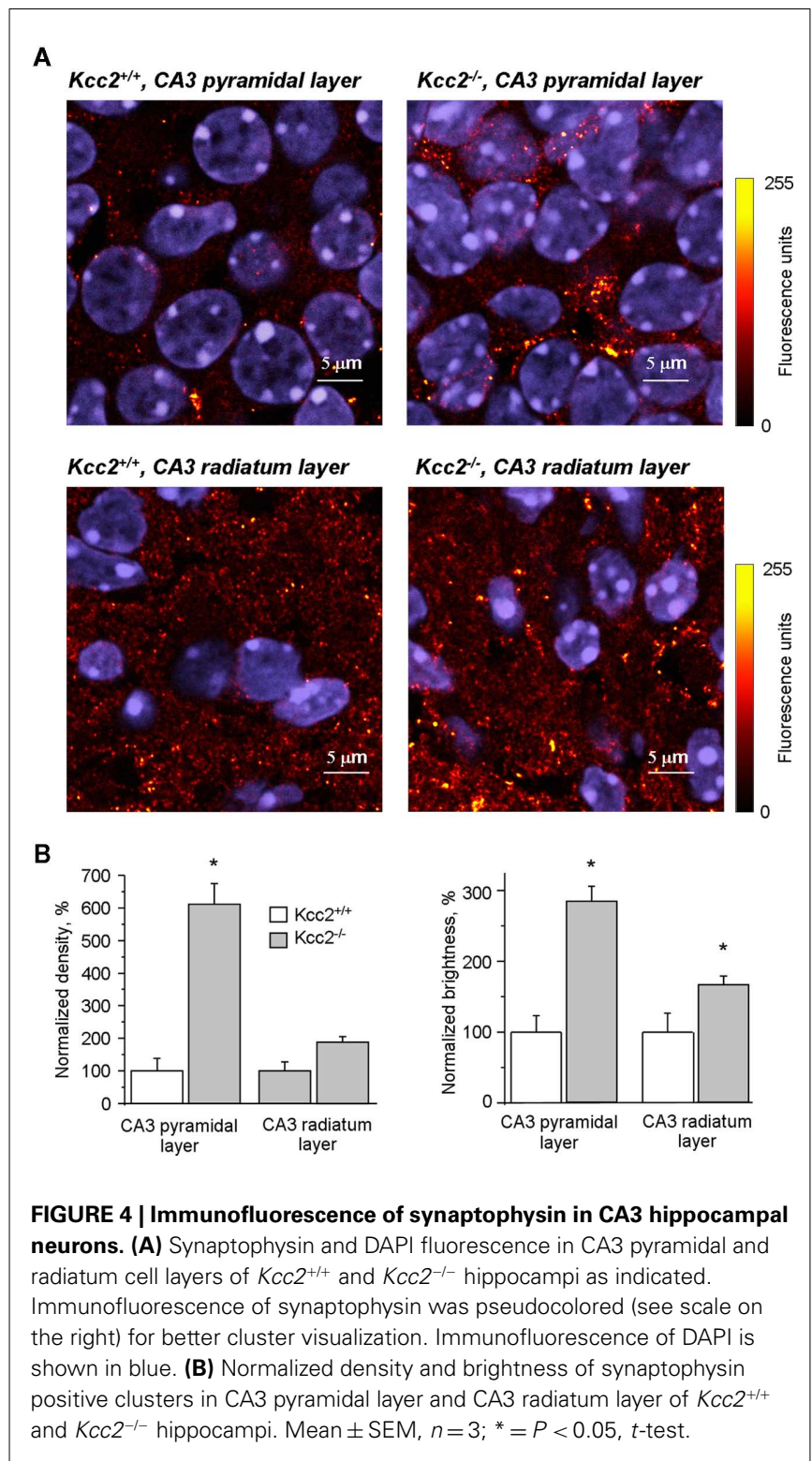

Blind analysis revealed that $K c c 2$ silencing induced a sixfold increase in the density of synaptophysin-positive clusters in CA3 pyramidal layer and twofold increase in CA3 stratum radiatum layer (Figure 4B, left panel). Moreover, in addition to increase of cluster density, there was also a significant increase of cluster brightness in $\mathrm{Kcc}^{-/-}$sections (2.8-fold in pyramidal layer and 1.6-fold in radiatum layer; Figure 4B, right panel) indicating an enhanced synapse formation in $\mathrm{Kcc}^{-/-}$versus $\mathrm{Kcc}^{+/+}$mice. Thus, KCC2 controls the development of synaptic connections in the embryonic mice hippocampi.

\section{EMBRYONIC KCC2 IMMUNOLABELING IS CYTOPLASMIC IN MOST NEURONS}

As shown in Figure 5A, KCC2 was clearly detectable in CA3 pyramidal region of $K c c 2^{+/+}$already 1 day before birth (E18.5), but not in $\mathrm{Kcc}^{-/-}$hippocampi. In E18.5 sections the average intensity of KCC2 immunofluorescence in both CA3 pyramidal and radiatum layers was at least twofold higher than the background fluorescence measured in $\mathrm{Kcc}^{-1-}$ sections and constituted approximately $50 \%$ of the KCC2 immunofluorescence measured in sections obtained from older (P7) $\mathrm{Kcc}^{+/+}$animals (Figure 5B). At E18.5 the KCC2-positive immunofluorescence was detected in $13.1 \pm 1.9 \%$ $(n=3)$ of CA3 pyramidal neurons (Figure 5C). In the remaining $86.9 \pm 1.9 \%$, the level of KCC2 immunofluorescence was within the range of background variability ( $<$ mean $+3 \mathrm{SD}$; Figure 5C). Among KCC2-positive neurons, in the majority of cells the labeling was localized in the cytoplasm (Figure 5A, insert i1). Only $17.8 \%$ of KCC2-positive neurons (corresponding to $2.3 \pm 0.5 \%$ of all analyzed neurons) included KCC2 in membrane region (Figure 5A, insert i2). Consistent with previous reports (Rivera et al., 1999; Stein et al., 2004), the expression of the KCC2 increased during development: at P7 $82.7 \pm 0.9 \%$ neurons were KCC2-positive and $79.3 \%$ of these neurons expressed KCC2 in their membrane region (Figure 5A, insert i4 and Figure 5C).

Thus, already during embryonic hippocampal development, there is an expression of the KCC2 in individual neurons of CA3 pyramidal layer that is mainly localized in the cytoplasm. Some neurons at this stage of development start to express KCC2 in membrane region.

\section{E $_{\text {GABA }}$ IS DEPOLARIZING IN Kcc2 $^{+/+}$AND Kcc2 $^{-/-}$MICE}

Earlier studies using perforated patch-clamp recordings [at P1-P3 (Stein et al., 2004)] or single channel analysis (Tyzio et al., 2007) have shown that $\mathrm{E}_{\mathrm{GABA}}$ was strongly depolarizing in embryonic CA3 and CA1 pyramidal neurons, respectively. Using gramicidineperforated patch-clamp recordings, we did not find a significant difference between $\mathrm{E}_{\mathrm{GABA}}$ recorded from $\mathrm{CA} 3$ neurons of $\mathrm{Kcc}^{+/+}$ and $K c c 2^{-1-}$ embryonic hippocampi $(P=0.87$, Figure 5D) confirming that $\left[\mathrm{Cl}^{-}\right]_{\mathrm{i}}$ is not regulated at this early developmental stage by KCC2. It is however possible that in naïve neurons KCC2 plays an important role in a small subpopulation of neurons (see Discussion).

\section{DISCUSSION}

The most conspicuous result of our study is that the ongoing neuronal activity is dramatically increased in hippocampi isolated from $\mathrm{Kcc}^{-1-}$ embryos when compared to age matched naïve structures. $K c c 2^{-1-}$ embryonic CA3 neurons express more GABA-ergic and glutamatergic PSCs, possess higher density of synaptic connections and show generation of epileptiform activities. Clearly, abolishing KCC2 accelerates synapse formation and enhances neuronal and network activity, suggesting that KCC2 modulates neuronal maturation, synapse formation and network operation at embryonic stage. The generation of epileptiform activities by networks deprived of KCC2 may impact the construction of functional networks illustrating the importance of this co-transporter for proper murine hippocampus development already in utero. This finding is not readily compatible with the suggested lack of embryonic function of the co-transporter (see Medina and Chudotvorova, 2006; Blaesse et al., 2009 for review). We show that although KCC2 does not appear to regulate 


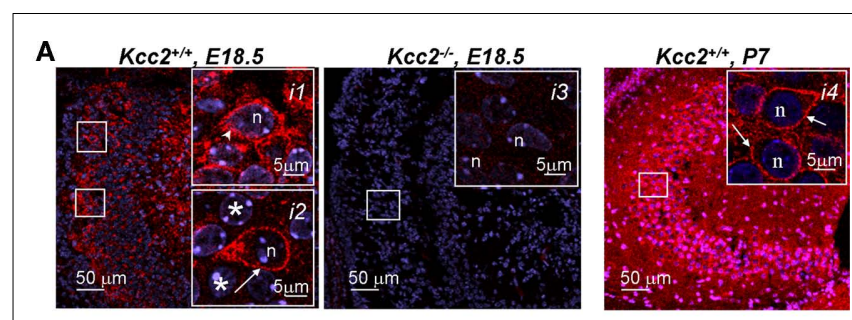

B CA3 pyramidal layer
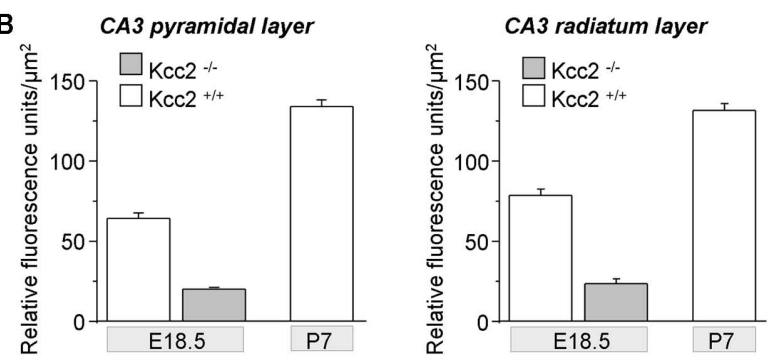

C

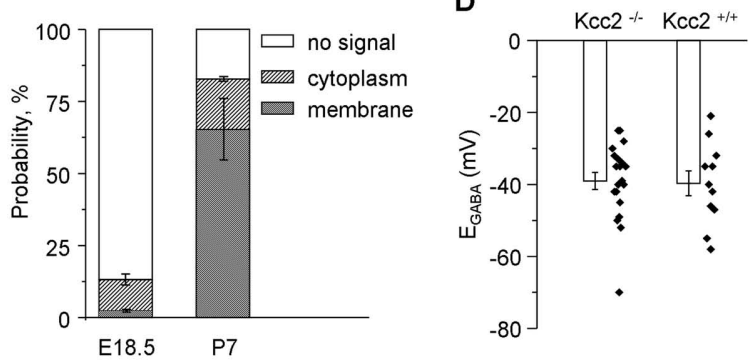

Figure-5 Khalilov

FIGURE 5 | Expression of the KCC2 in CA3 hippocampal neurons. (A) Immunoreactivity of $\mathrm{KCC} 2$ (red) in CA3 pyramidal neurons of $\mathrm{KCC}^{+/+}$and $\mathrm{KCC}^{-1-}$ mouse as indicated. Notice the absence of the KCC2-positive immunoreactivity in $\mathrm{Kcc} 2^{-/-}$samples characterizing high specificity of the antibody. The arrowhead in insert i1 illustrates typical KCC2-positive CA3 neuron in $\mathrm{E} 18.5 \mathrm{KcC2} 2^{+/+}$hippocampi with immunoreactivity localized in cytoplasm. Asterisks in insert i2 indicate KCC2-negative neurons, whereas arrow indicates a rare neuron with KCC2 immunoreactivity localized in membrane region. For comparison, insert i4 illustrates a typical KCC2 immunoreactivity distribution in CA3 neurons of P7 $\mathrm{Kcc} 2^{+/+}$mouse that is localized in most of neurons in membrane region (shown by arrows). $\mathrm{n}=$ nucleus. (B) Quantification of the KCC2 immunoreactivity in CA3 pyramidal and radiatum layers of $K c c 2^{-/-}$(E18.5) and $K c C 2^{+/+}$(E18.5 and P7) hippocampi. Mean $\pm S E M, n=3$. The difference between any two values in both plots is highly significant $(P<0.01$, $t$-test). (C) Age-dependent distribution of neurons' populations expressing KCC2 in membrane region ("membrane"), in the cytoplasm only ("cytoplasm"), and without detectable KCC2 immunoreactivity ("no signal"). Normalized values obtained after analysis of 50-100 neurons per animal, $n=3 \mathrm{Kcc} 2^{+/+}$mice per age. The background (no signal) level of fluorescence was determined after analysis of the immunofluorescence of sections prepared from E18.5 $K c c 2^{-1-}$ mice ( $n=3$; see Materials and Methods for details on fluorescence analysis). (D) Reversal potential of isoguvacine-induced responses in CA3 hippocampal neurons measured using gramicidin-perforated patch-clamp recording. Mean $\pm S E M, n=6$ mice per condition, two to four neurons per mouse. Dots show values in individual measurements. There was no difference in mean values of $E_{G A B A}$

intracellular chloride levels (but see below), its inactivation leads to change of neuronal network and, thus, raises important issues concerning its embryonic roles. Interestingly, genetic ablation of the NKccl chloride importer delays brain development with less functional synapses (Pfeffer et al., 2009; Marissal, Ben-Ari, unpublished data), but also see Sipila et al. (2006) suggesting that the two co-transporters act in opposite directions on these parameters as well.

\section{CHLORIDE INDEPENDENT ACTIONS OF KCC2 ON EMBRYOS}

There is a general consensus that the expression of the KCC2 starts during postnatal stages of the development of hippocampi in rat and mice (Stein et al., 2004; Blaesse et al., 2006; Zhu et al., 2008). This also implies a progressive externalization of the cotransporter possibly mediated by a developmental sequence of the phosphorylation mechanisms recently reported (Rinehart et al., 2009; Lee et al., 2010). Our observations of a similar $\mathrm{E}_{\mathrm{GABA}}$ in $K c c 2^{-/-}$and $K c c 2^{+/+}$is in keeping with this suggestion and with the largely depolarizing action of GABA at early stages (Ben-Ari et al., 2007). A recent study elegantly showed that a regulatory action of KCC2 in immature neurons might indeed develop through an ion transport-independent mechanism, as the overexpression of inactive $\mathrm{N}$-terminus KCC2 deleted construct produced similar to wild-type KCC2 effects (Horn et al., 2010). Similar results, but different conclusions concerning the mechanisms of KCC2 action, were obtained by Cancedda et al. (2007) who showed that viral overexpression of the KCC2 in immature cortical neurons slows-down neuronal maturation. Our work is the first study showing that endogenous KCC2 and not only artificially expressed $\mathrm{KCC} 2$, regulate maturation in immature neurons.

\section{ALTERNATIVE POSSIBILITIES OF REGULATORY ACTIONS OF KCC2 IN EMBRYONIC HIPPOCAMPUS}

Can we completely exclude the contribution of chloride shifts in the effects of KCC2 ablation? The finding that a GABA receptor antagonist generates epileptiform activities in naïve neurons - after long-lasting applications - but block fully ongoing activities generated by $\mathrm{Kcc}^{-1-}$ embryos is intriguing as it suggests that excitatory actions of GABA are enhanced in the Kcc2 deficient in comparison to control mice. This stands in apparent contradiction with the similar $\mathrm{E}_{\mathrm{GABA}}$ in $K c c 2^{-/-}$and $K c c 2^{+/+}$. However, there are many observations showing that chloride levels play important roles at embryonic stages in selective cell populations. Thus, in developing neocortex, while the majority of pyramidal cells and interneurons are KCC2-negative, some interneurons express high amount of KCC2 and the activity of this transporter orchestrates interneuron migration (Bortone and Polleux, 2009). In keeping with this, bicuculline alters neuronal migration in vitro (Manent et al., 2005). In the present work we report an existence of small population of neurons with KCC2 expressed in membrane region (Figure 5). Thus, one chloride-based alternative possibility is that the loss of the co-transporter affects a subpopulation of neurons impacting the entire network. One more possibility could be that naïve KCC2-positive neurons exhibit difference in $\left[\mathrm{Cl}^{-}\right]_{\mathrm{i}}$ homeostasis on the level of dendrites, but not soma. Studies show the existence of KCC2-dependent somato-dendritic gradient of chloride in mature hippocampal neurons (Khirug et al., 2008; Pellegrino et al., 2011). Testing these hypotheses would require the development of appropriate models allowing $\left[\mathrm{Cl}^{-}\right]_{\mathrm{i}}$ measurement 
in different neuronal compartments as well as suppression of the KCC2 in different neuron subpopulations during embryonic development.

\section{AGE RESTRICTED REGULATORY ACTIONS OF KCC2}

Our results show clearly that ablation of KCC2 enhances synaptogenesis in the immature hippocampus, i.e., endogenous KCC2 inhibits formation of the synaptic connections and neuronal network activity. This finding is in a good agreement with previous reports by Cancedda et al. (2007) and Horn et al. (2010) illustrating that in vivo overexpression of $\mathrm{KCC} 2$ in immature neurons slows-down neuronal development. Interestingly, all these results are in apparent contradiction with previous reports performed on primary neuronal cultures and showing that KCC2 is required for formation of GABA and glutamate synaptic connections. Particularly, we found that overexpression of KCC2 in immature neurons potentiated formation of GABA-ergic synapses (Chudotvorova et al., 2005) whereas knocking-out or knocking-down of KCC2 from cultured hippocampal neurons produced opposite effects (Medina et al., 2011). Another set of data show that the knockingout (Li et al., 2007) or knocking-down (Gauvain et al., 2011) of the KCC2 in mature primary neuronal hippocampal cultures lead to structural modification in spines formation and decrease glutamatergic synaptic transmission. The overexpression of the KCC2 in these cultures rescued (i.e., potentiated) formation of glutamate synapses. An important task for future studies would be to determine the reason of this differential KCC2-dependent control of synaptogenesis in immature hippocampal neurons in vivo and mature hippocampal neurons in vitro.

In conclusion, we show that there is a prominent difference in neuronal network activity and formation of the functional GABA and glutamate synapses in immature CA3 hippocampal neurons

\section{REFERENCES}

Ben-Ari, Y., Cherubini, E., Corradetti, R., and Gaiarsa, J. L. (1989). Giant synaptic potentials in immature rat CA3 hippocampal neurones. J. Physiol. (Lond.) 416, 303-325.

Ben-Ari, Y., Gaiarsa, J. L., Tyzio, R., and Khazipov, R. (2007). GABA: a pioneer transmitter that excites immature neurons and generates primitive oscillations. Physiol. Rev. 87, 1215-1284.

Blaesse, P., Airaksinen, M. S., Rivera, C., and Kaila, K. (2009). Cationchloride cotransporters and neuronal function. Neuron 61, 820-838.

Blaesse, P., Guillemin, I., Schindler, J., Schweizer, M., Delpire, E., Khiroug, L., Friauf, E., and Nothwang, H. G. (2006). Oligomerization of KCC2 correlates with development of inhibitory neurotransmission. $J$. Neurosci. 26, 10407-10419.

Bortone, D., and Polleux, F. (2009). KCC2 expression promotes the termination of cortical interneuron migration in a voltage-sensitive calcium-dependent manner. Neuron $62,53-71$.
Caiati, M. D., Sivakumaran, S., and Cherubini, E. (2010). In the developing rat hippocampus, endogenous activation of presynaptic kainate receptors reduces GABA release from mossy fiber terminals. J. Neurosci. 30, 1750-1759.

Cancedda, L., Fiumelli, H., Chen, K., and Poo, M. M. (2007). Excitatory GABA action is essential for morphological maturation of cortical neurons in vivo. J. Neurosci. 27, 5224-5235.

Cherubini, E., Griguoli, M., Safiulina, V., and Lagostena, L. (2011). The depolarizing action of GABA controls early network activity in the developing hippocampus. Mol. Neurobiol. 43, 97-106.

Chudotvorova, I., Ivanov, A., Rama, S., Hubner, C. A., Pellegrino, C., Ben Ari, Y., and Medina, I. (2005). Early expression of KCC2 in rat hippocampal cultures augments expression of functional GABA synapses. $J$. Physiol. (Lond.) 566, 671-679.

Cohen, I., Navarro, V., Clemenceau, S., Baulac, M., and Miles, R. (2002). On the origin of interictal activity

of wild-type and $K c c 2$ deficient mice embryos. This finding provides a novel point of view on the functional importance of KCC2 during early stages of neuronal network development when GABA is still depolarizing and opens new attractive directions in study of the mechanisms of KCC2 functioning.

\section{AUTHORS CONTRIBUTION}

Ilgam Khalilov, Romain Nardou, and Jean-Luc Gaiarsa performed recordings from entire hippocampi and acute hippocampal slices. Geneviève Chazal and Nadine Ferrand performed quantitative immunofluorescence analyses. Ilona Chudotvorova, Séverine Corby, Olena Gubkina, Christophe Pellegrino took care of the Kcc2 deficient mice at the INMED at different stages of the work, made genotyping and part of the immunocytochemistry study. Sumii Yamamoto, Roman Tyzio, and Christophe Pellegrino performed analysis of $\left[\mathrm{Cl}^{-}\right]_{\mathrm{i}}$ using different approaches. Thomas J Jentsch, Christian A Hübner, created Kcc2 deficient mouse, developed antiKCC2 antibody, performed part of the immunocytochemistry study. Yehezkel Ben-Ari contributed to writing the manuscript and management of the experiments involving recording and analysis of $\left[\mathrm{Cl}^{-}\right]_{\mathrm{i}}$ from acute slices and spontaneous activity from entire hippocampi. Igor Medina was in charge of management of the project, writing manuscript, and performed part of the whole-cell recordings from acute slices.

\section{ACKNOWLEDGMENTS}

We are grateful to Diabé Diabira for excellent technical assistance. This study was supported by grants from the French Agence Nationale pour la Recherche (to Ilgam Khalilov, Igor Medina, and Jean-Luc Gaiarsa), the French Fondation pour la Recherche Médicale (to Ilona Chudotvorova and Romain Nardou), and NEMO EU FP7 grant (Yehezkel Ben-Ari).

in human temporal lobe epilepsy in vitro. Science 298, 1418-1421.

Gauvain, G., Chamma, I., Chevy, Q., Cabezas, C., Irinopoulou, T., Bodrug, N., Carnaud, M., Levi, S., and Poncer, J. C. (2011). The neuronal K-Cl cotransporter KCC2 influences postsynaptic AMPA receptor content and lateral diffusion in dendritic spines. Proc. Natl. Acad. Sci. U.S.A. 108, 15474-15479.

Gulyas, A. I., Sik, A., Payne, J. A., Kaila, K., and Freund, T. F. (2001). The $\mathrm{KCl}$ cotransporter, $\mathrm{KCC} 2$, is highly expressed in the vicinity of excitatory synapses in the rat hippocampus. Eur. J. Neurosci. 13, 2205-2217.

Horn, Z., Ringstedt, T., Blaesse, P., Kaila, K., and Herlenius, E. (2010). Premature expression of KCC2 in embryonic mice perturbs neural development by an ion transportindependent mechanism. Eur. J. Neurosci. 31, 2142-2155.

Hubner, C. A., Stein, V., HermansBorgmeyer, I., Meyer, T., Ballanyi, K., and Jentsch, T. J. (2001). Disruption of KCC2 reveals an essential role of $\mathrm{K}-\mathrm{Cl}$ cotransport already in early synaptic inhibition. Neuron 30 , 515-524.

Khalilov, I., Dzhala, V., Ben-Ari, Y., and Khazipov, R. (1999). Dual role of GABA in the neonatal rat hippocampus. Dev. Neurosci. 21, 310-319.

Khalilov, I., Esclapez, M., Medina, I., Aggoun, D., Lamsa, K., Leinekugel, X., Khazipov, R., and Ben Ari, Y. (1997). A novel in vitro preparation: the intact hippocampal formation. Neuron 19, 743-749.

Khalilov, I., Holmes, G. L., and Ben Ari, Y. (2003) In vitro formation of a secondary epileptogenic mirror focus by interhippocampal propagation of seizures. Nat. Neurosci. 6, 1079-1085.

Khirug, S., Huttu, K., Ludwig, A., Smirnov, S., Voipio, J., Rivera, C., Kaila, K., and Khiroug, L. (2005). Distinct properties of functional KCC2 expression in immature mouse hippocampal neurons in culture and in acute slices. Eur. J. Neurosci. 21, 899-904. 
Khirug, S., Yamada, J., Afzalov, R., Voipio, J., Khiroug, L., and Kaila, K. (2008). GABAergic depolarization of the axon initial segment in cortical principal neurons is caused by the Na-K-2Cl cotransporter NKCC1. J. Neurosci. 28, 4635-4639.

Lee, H. H., Jurd, R., and Moss, S. J. (2010). Tyrosine phosphorylation regulates the membrane trafficking of the potassium chloride cotransporter KCC2. Mol. Cell. Neurosci. 45, 173-179.

Leinekugel, X., Khalilov, I., McLean, H., Caillard, O., Gaiarsa, J. L., Ben-Ari, Y., and Khazipov, R. (1999). GABA is the principal fast-acting excitatory transmitter in the neonatal brain. Adv. Neurol. 79, 189-201.

Leinekugel, X., Medina, I., Khalilov, I., Ben Ari, Y., and Khazipov, R. (1997). Ca2+ oscillations mediated by the synergistic excitatory actions of $\operatorname{GABA}(\mathrm{A})$ and NMDA receptors in the neonatal hippocampus. $\mathrm{Neu}$ ron 18, 243-255.

Li, H., Khirug, S., Cai, C., Ludwig, A., Blaesse, P., Kolikova, J., Afzalov, R., Coleman, S. K., Lauri, S., Airaksinen, M. S., Keinanen, K., Khiroug, L., Saarma, M., Kaila, K., and Rivera, C. (2007). KCC2 interacts with the dendritic cytoskeleton to promote spine development. Neuron 56, 1019-1033.

Manent, J. B., Demarque, M., Jorquera, I., Pellegrino, C., Ben-Ari, Y., Aniksztejn, L., and Represa, A. (2005). A noncanonical release of GABA and glutamate modulates neuronal migration. J. Neurosci. 25, 4755-4765.

Medina, I., and Chudotvorova, I. (2006). GABA neurotransmission and neural cation-chloride cotransporters: actions beyond ion transport. Crit. Rev. Neurobiol. 18, 105-112.

Medina, I., Friedel, P., Chudotvorova, I., Pellegrino, C., Schaefer, M., and Porcher, C. (2011). A critical role of potassium/chloride co-transport in formation of functional GABA synapses. Soc. Neurosci. [Washington (Abstr.)], 545.08.

Nardou, R., Ben-Ari, Y., and Khalilov, I. (2009). Bumetanide, an NKCC1 antagonist, does not prevent formation of epileptogenic focus but blocks epileptic focus seizures in immature rat hippocampus. J. Neurophysiol. 101, 2878-2888.

Nardou, R., Yamamoto, S., Chazal, G., Bhar, A., Ferrand, N., Dulac, O., BenAri, Y., and Khalilov, I. (2011). Neuronal chloride accumulation and excitatory GABA underlie aggravation of neonatal epileptiform activities by phenobarbital. Brain 134, 987-1002.

Owens, D. F., and Kriegstein, A. R. (2002). Developmental neurotransmitters? Neuron 36, 989-991.

Payne, J. A., Stevenson, T. J., and Donaldson, L. F. (1996). Molecular characterization of a putative $\mathrm{K}-\mathrm{Cl}$ cotransporter in rat brain. A neuronal-specific isoform. J. Biol. Chem. 271, 16245-16252.

Pellegrino, C., Gubkina, O., Schaefer, M., Becq, H., Ludwig, A., Mukhtarov, M., Chudotvorova, I., Corby, S., Salyha, Y., Salozhin, S., Bregestovski, P., and Medina, I. (2011). Knocking down of the KCC2 in rat hippocampal neurons increases intracellular chloride concentration and compromises neuronal survival. J. Physiol. (Lond.) 589, 2475-2496.

Pfeffer, C. K., Stein, V., Keating, D. J., Maier, H., Rinke, I., Rudhard, Y., Hentschke, M., Rune, G. M., Jentsch, T. J., and Hubner, C. A. (2009). NKCC1-dependent GABAergic excitation drives synaptic network maturation during early hippocampal development. J. Neurosci. 29, 3419-3430.

Rinehart, J., Maksimova, Y. D., Tanis, J. E., Stone, K. L., Hodson, C. A., Zhang, J., Risinger, M., Pan, W., Wu, D., Colangelo, C. M., Forbush,
B., Joiner, C. H., Gulcicek, E. E., Gallagher, P. G., and Lifton, R. P. (2009). Sites of regulated phosphorylation that control K-Cl cotransporter activity. Cell 138, 525-536.

Rivera, C., Voipio, J., Payne, J. A., Ruusuvuori, E., Lahtinen, H., Lamsa, K. Pirvola, U., Saarma, M., and Kaila, K. (1999). The K+/Cl- co-transporter KCC2 renders GABA hyperpolarizing during neuronal maturation. Nature 397, 251-255.

Sipila, S. T., Schuchmann, S., Voipio, J., Yamada, J., and Kaila, K. (2006). The cation-chloride cotransporter NKCC1 promotes sharp waves in the neonatal rat hippocampus. $J$. Physiol. (Lond.) 573, 765-773.

Stein, V., Hermans-Borgmeyer, I., Jentsch, T. J., and Hubner, C. A. (2004). Expression of the $\mathrm{KCl}$ cotransporter KCC2 parallels neuronal maturation and the emergence of low intracellular chloride. J. Comp. Neurol. 468, 57-64.

Tyzio, R., Holmes, G. L., Ben-Ari, Y., and Khazipov, R. (2007). Timing of the developmental switch in GABA(A) mediated signaling from excitation to inhibition in CA3 rat hippocampus using gramicidin perforated patch and extracellular recordings. Epilepsia 48(Suppl. 5), 96-105.

Tyzio, R., Ivanov, A., Bernard, C. Holmes, G. L., Ben Ari, Y., and Khazipov, R. (2003). Membrane potential of $\mathrm{CA} 3$ hippocampal pyramidal cells during postnatal development. J. Neurophysiol. 90, 2964-2972.

Tyzio, R., Represa, A., Jorquera, I., BenAri, Y., Gozlan, H., and Aniksztejn, L. (1999). The establishment of GABAergic and glutamatergic synapses on CA1 pyramidal neurons is sequential and correlates with the development of the apical dendrite. J. Neurosci. 19, 10372-10382.

Williams, J. R., Sharp, J. W., Kumari, V. G., Wilson, M., and Payne, J. A. (1999). The neuron-specific
K-Cl cotransporter, KCC2. Antibody development and initial characterization of the protein. J. Biol. Chem. 274, 12656-12664.

Wittner, L., Huberfeld, G., Clemenceau, S., Eross, L., Dezamis, E., Entz, L., Ulbert, I., Baulac, M., Freund, T. F., Magloczky, Z., and Miles, R. (2009). The epileptic human hippocampal cornu ammonis 2 region generates spontaneous interictal-like activity in vitro. Brain 132, 3032-3046.

Zhu, L., Polley, N., Mathews, G. C., and Delpire, E. (2008). NKCC1 and KCC2 prevent hyperexcitability in the mouse hippocampus. Epilepsy Res. 79, 201-212.

Conflict of Interest Statement: The authors declare that the research was conducted in the absence of any commercial or financial relationships that could be construed as a potential conflict of interest.

Received: 24 August 2011; paper pending published: 09 September 2011; accepted: 13 October 2011; published online: 01 November 2011.

Citation: Khalilov I, Chazal G, Chudotvorova I, Pellegrino C, Corby $S$, Ferrand $N$, Gubkina O, Nardou $R$, Tyzio R, Yamamoto S, Jentsch TJ, Hübner CA, Gaiarsa J-L, Ben-Ari $Y$ and Medina I (2011) Enhanced synaptic activity and epileptiform events in the embryonic KCC2 deficient hippocampus. Front. Cell. Neurosci. 5:23. doi: 10.3389/fncel.2011.00023

Copyright (c) 2011 Khalilov, Chazal, Chudotvorova, Pellegrino, Corby, Ferrand, Gubkina, Nardou, Tyzio, Yamamoto, Jentsch, Hübner, Gaiarsa, Ben-Ari and Medina. This is an openaccess article subject to a non-exclusive license between the authors and Frontier Media SA, which permits use, distribution and reproduction in other forums, provided the original authors and source are credited and other Frontiers conditions are complied with. 